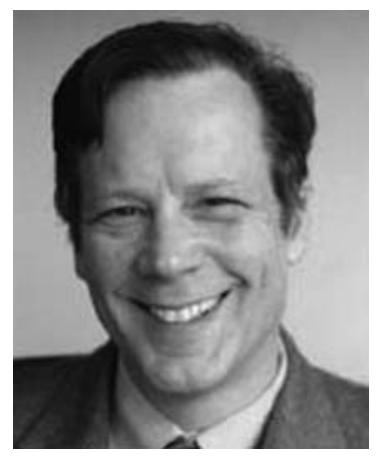

\title{
A Conversation with Robert Desimone
}

\author{
INTERVIEWER: ANN GoLDSTEIN \\ Scientific Editor, Neuron
}

Robert Desimone is Director of the McGovern Institute and the Doris and Don Berkey Professor in the Department of Brain and Cognitive Sciences.

\begin{abstract}
Ann Goldstein: As one of the few that study both humans and nonhuman primates, how has your lab's use of both systems helped inform your work in ways that were unexpected or inspiring?
\end{abstract}

Dr. Desimone: We always start with human behavior. Something in human behavior that we want to try to explain is related to attention these days. Often the human behavioral work has been done-we've done a little bit ourselves, but there's a huge field of human behavioral work and attention. Then we look at how human neuroscience studies have informed us. Sometimes there are open questions in which case we jump in ourselves. In other situations, there's sufficient information that we can go to an animal study because there the goal is to try to link what we see in humans to the underlying neuronal circuitry, which you can't do in human beings. We're getting much better at human techniques like magnetoencephalography (MEG) combined with fMRI. We don't do electrocorticography recordings, but a lot of labs are starting to do that and I think that's super exciting, but you can't get to that level of neural circuits in humans, so we do the monkey studies to provide that link.

Ann Goldstein: How did your combination of fMRI and MEG change the way you approach your work?

Dr. Desimone: When I was at the NIH, over 9 years ago, I pushed for an MEG machine and did some pilot studies. At MIT, we got our machine a little over a year ago, and my lab was one of the first users. One of my postdocs, Daniel Baldauf, who had not worked with MEG before, had to learn not only all that is already known about analyzing MEG data, but had to invent a lot of his own techniques because that's an area that's much less developed than techniques for analyzing fMRI data. He did a huge amount of developmental work and then we started the studies on attention. MEG gives us the exact timing of activity and that's the reason for doing animal work because you need that exact timing.

The fMRI gives you the spatial localization, and the fMRI is usually limited to a second or two. Just think about all the operations your brain can carry out in a second, all the decision-making, reaction, switching, and so on, but MEG is working at the millisecond level, the sort of level at which our brains actually operate.

Ann Goldstein: What do you see as the future for understanding attention and its dysfunction?

Dr. Desimone: One of the things we identified in our latest human study is the important role the prefrontal cortex is playing in the regulation of sensory processing with object feature based attention. The prefrontal cortex always comes at the top of everyone's list for what might play a role in a lot of human psychiatric and neurological disorders. It's the most developed part of the human brain, it's large compared to the prefrontal cortex in the monkey, but compared to the mouse, which many people are using, it's many orders of magnitude larger. The mouse has a tiny prefrontal cortex. What makes us human is really that massive prefrontal cortex. It's clearly very much involved in attention and attention is very much involved in all these psychiatric disorders.

People who are depressed complain about lack of attention, focus, concentration. So do people with lots of learning disorders, most obviously attention deficit disorder. Focusing, keeping on track, blocking out distraction-we all have a problem with these functions, but people with psychiatric disorders often have an even worse problem. It's focused our attention on this part of the brain, and we'd like to be doing studies on that. 
Ann Goldstein: Since you have an interest in the effects of overabundant information, how do we deal with this very fast information age we live in now with lots of mobile technology, video games, and so on?

Dr. Desimone: My advice will sound totally trivial, but I recommend trying not to use your brain to block out all that distraction. Instead try to eliminate it from the environment. You will be infinitely better off. Remove the TV or radio in the background and all those other sorts of things, because filtering that out takes a lot of your brain's energy and a lot of your cognitive focus. You'd be better off having that cognitive capacity devoted to whatever you're trying to do, the problem at hand. 


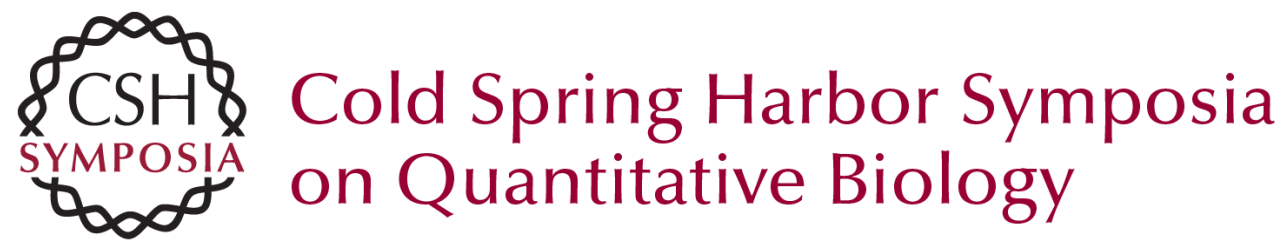

\section{A Conversation with Robert Desimone}

Cold Spring Harb Symp Quant Biol 2014 79: 269-270

Access the most recent version at doi:10.1101/sqb.2014.79.08

\section{License}

Email Alerting Receive free email alerts when new articles cite this article - sign up in Service the box at the top right corner of the article or click here. 